\title{
Effectiveness of lionfish removal efforts in the southern Caribbean
}

\author{
Ramón de León ${ }^{1}$, Kim Vane ${ }^{2}$, Paulo Bertuol ${ }^{1}$, Valérie C. Chamberland ${ }^{2,3}$, \\ Fernando Simall ${ }^{1}$, Eseld Imms ${ }^{4}$, Mark J. A. Vermeij ${ }^{2,3, *}$ \\ ${ }^{1}$ STINAPA Bonaire, Bonaire National Marine Park, Barcadera z/n, Kralendijk, Bonaire, Dutch Caribbean \\ ${ }^{2}$ CARMABI Foundation, PO Box 2090, Piscaderabaai z/n, Willemstad, Curaçao \\ ${ }^{3}$ Aquatic Microbiology, Institute for Biodiversity and Ecosystem Dynamics, University of Amsterdam, Science Park 700, \\ 1098 XH Amsterdam, The Netherlands \\ ${ }^{4}$ Dutch Caribbean Nature Alliance, Kralendijk, Bonaire, Dutch Caribbean
}

\begin{abstract}
Lionfish Pterois volitans and P. miles have spread rapidly throughout the Caribbean Sea since 1985, where they negatively impact native fish communities and therefore are considered by some as the most damaging invasive species in the Caribbean to date. To combat further population growth and spread of lionfish and to protect native fish communities, various Caribbean islands have started control efforts. On Bonaire, a removal program based on volunteers using spear guns was started immediately after the first lionfish was sighted in 2009, and a similar program was started on neighboring Curaçao 2 yr later. To determine the effectiveness of these removal efforts, differences in the density and biomass of lionfish were compared between areas in which lionfish were directly targeted during removal efforts (i.e. 'fished' areas) on Bonaire and areas where they were not (i.e. 'unfished areas') on both Bonaire and Curaçao. Lionfish biomass in fished locations on Bonaire was 2.76-fold lower than in unfished areas on the same island and 4.14-fold lower than on unfished Curaçao. While removal efforts are effective at reducing the local number of lionfish, recruitment from unfished locations, such as those too deep for recreational diving and at dive sites that are difficult to access, will continuously offset the effects of removal efforts. Nevertheless, our results show that the immediate start and subsequent continuation of local removal efforts using volunteers is successful at significantly reducing the local density and biomass of invasive lionfish on small Caribbean islands.
\end{abstract}

KEY WORDS: Spearfishing · Eradication of lionfish $\cdot$ Pterois volitans $\cdot$ Invasive species $\cdot$ Curaçao · Bonaire

\section{INTRODUCTION}

Eradicating and controlling populations of marine invasive species has been shown to be a challenging task. In contrast to terrestrial invasions, experiences with and methods to deal with marine invasions are limited (Bax et al. 2001, Secord 2003), and while some management efforts on land have been successful, relatively few marine invaders have been fully removed from their non-native range (Culver \& Kuris 2000, Bax et al. 2001, Secord 2003, Wotton et al. 2004, Anderson 2005, Genovesi 2005). Full removal or control of marine invasives is complicated by the ability of marine invasives to disperse across large distances (e.g. through currents or in ballast water), limited financial and physical resources in areas where invasions have occurred and a persistent reservoir of invasives in remote or hard to access locations (Lafferty \& Kuris 1996, Johnston et al. 2009). Furthermore, given the large dispersal potential of marine invasives, management of such species often requires international collaboration to ensure effective control (Bax et al. 2003, Hewitt et al. 2009). However, creating such collaborative networks takes 
time, and as a result, local and rapid response efforts are often not sufficiently considered as a (temporary) alternative to international action to minimize the effect of marine invasives, despite the fact that such rapid response strategies are sometimes successful (Anderson 2005, Frazer et al. 2012).

All aforementioned aspects are relevant to management efforts aimed at minimizing the negative effects of the invasive Pacific lionfish Pterois volitans and $P$. miles on native marine communities in the Atlantic Ocean. $P$. volitans/miles were first sighted in the Atlantic region near the southeast coast of North America in 1985, where they had likely been released by aquarists (Semmens et al. 2004). From there, they first spread northward along the east coast of the USA and since 2004 also southward toward the Caribbean Sea, the Gulf of Mexico and the north coast of South America (Schofield 2009, 2010, Johnston \& Purkis 2011, Frazer et al. 2012). In the Caribbean, lionfish have established themselves in a variety of marine habitats, including coral reefs, mangroves, sea grass beds, coastal estuaries and deep waters up to $300 \mathrm{~m}$ (Barbour et al. 2010, Biggs \& Olden 2011, Jud et al. 2011). They are generalist predators of small and juvenile fish (Albins \& Hixon 2008, Morris \& Akins 2009, Côté \& Maljković 2010, Green et al. 2011, Muñoz et al. 2011, Layman \& Allgeier 2012, Valdez-Moreno et al. 2012) and characterized by higher predation rates than similarly sized native predators with similar life-history characteristics (Albins 2013). In most areas, natural control of lionfish is unlikely as overfishing has reduced the number of native predators potentially capable of consuming them, e.g. Atlantic grouper species (Maljković et al. 2008, Mumby et al. 2011). The density of Atlantic lionfish presently exceeds that in its native range (the Pacific and Indian Oceans) by a factor of 13 to 15 (Darling et al. 2011, Kulbicki et al. 2012), which is attributed to factors such as the species' high fecundity and low parasite load, in addition to the absence of potential native predators (Fishelson 1975, Morris 2009, Morris et al. 2011a, Albins \& Hixon 2013). It has been suggested that invasive lionfish may become one of the most ecologically harmful marine fish introductions to date (Albins \& Hixon 2013).

While consensus has been reached that the lionfish has established itself permanently in both the Caribbean and the wider Western Atlantic, various management agencies have proposed measures to reduce and/or control the local lionfish abundance to reduce their negative impact on native fish populations (Albins \& Hixon 2008, Côté \& Maljković 2010,
Arias-González et al. 2011, Green et al. 2011, Muñoz et al. 2011). Most strategies aimed at reducing local lionfish abundance involve some form of controlled or managed (spear) fishing by SCUBA divers and snorkelers who target lionfish independently or in organized groups (Frazer et al. 2012). In addition, the consumption of lionfish is being promoted, and a commercial fishery for lionfish has been proposed to ensure constant fishing pressure on lionfish populations (Albins \& Hixon 2013, Muñoz et al. 2011).

On Bonaire and Curaçao, 2 sister islands in the southern Caribbean, the first official lionfish sighting occurred on 26 October 2009 on Bonaire and the following day on Curaçao. On Bonaire, the National Parks Foundation (STINAPA) immediately started active removal efforts by training $\sim 300$ local recreational divers to kill lionfish using modified spear guns (Eradicate Lion Fish [ELFs $\left.{ }^{\mathrm{TM}}\right]$ ). On Curaçao, a similar program was started by the Curaçaoan Ministry of Health, Environment and Nature in July 2011, which eventually resulted in 70 divers trained similarly as those on Bonaire. Spearfishing is illegal on both islands, and local authorities provided divers participating in aforementioned efforts with special permits allowing the spearing of lionfish using ELFs only.

To determine the effectiveness of these removal efforts, differences in the density and biomass of lionfish were compared between areas in which lionfish were directly targeted during removal efforts (i.e. 'fished' areas) on Bonaire and areas where they were not (i.e. 'unfished areas') on both Bonaire and Curaçao between June and August 2011. For the purpose of the present study, we will use the term 'unfished' for sites that were not targeted during eradication efforts but that likely experienced some moderate form of fishing by individuals diving away from traditional dive sites in search of dense lionfish populations. Bonaire and Curaçao are only $41 \mathrm{~km}$ apart, occur in the same physicochemical province (Chollett et al. 2012) and have very similar reef community structure (van Duyl 1985, Van Veghel 1997, Sandin et al. 2007). Lionfish appeared on both islands in October 2009, suggesting that the influx of new individuals by currents is roughly similar between both islands. Given the aforementioned similarities, we assume that for the context of the present study, fishing pressure on lionfish is the main factor that differs between the 2 islands that affects the density and biomass of lionfish. Density and biomass of lionfish were quantified across a depth gradient on both islands in fished (Bonaire) and unfished (Bonaire and Curaçao) sites along each island's leeward shore. 


\section{MATERIALS AND METHODS}

\section{Study sites}

Fieldwork was conducted from June to August 2011 on the leeward side of Bonaire $\left(12^{\circ} \mathrm{N}, 68^{\circ} \mathrm{W}\right)$ and Curaçao $\left(12^{\circ} \mathrm{N}, 69^{\circ} \mathrm{W}\right)$ in the southern Caribbean. The windward shores of both islands are generally non-accessible to divers due to high wave action and high rocky shores. In contrast, the fringing reefs on the leeward (southwestern) shores are characterized by relatively calm conditions and are easily accessible from shore year-round. As a consequence, lionfish removal efforts are concentrated foremost on the leeward sides of both islands. On Bonaire, a distinction between fished and unfished areas was made. Fishing of lionfish commonly occurs on easily accessible and popular dive sites and house reefs of dive operators. It is assumed that divers generally move no more than $150 \mathrm{~m}$ from the location where they entered the water in a single dive (Hawkins et al. 1999, Rouphael \& Inglis 2002). Such frequently visited areas, where divers enter the water at marked and therefore consistent locations, are hereafter considered fished areas. Areas that are relatively unfished or less fished compared to fished areas are assumed to start at least $200 \mathrm{~m}$ away from regular entry points in any direction and are from here on referred to as 'unfished' sites. STINAPA maintains an online database where volunteers enter number and location data for the lionfish they caught (see www. lionfishcontrol.org). These data were used to test our assumption that the majority of lionfish were indeed caught within $150 \mathrm{~m}$ of entries or buoys of marked dive sites. This database contains total catch data from October 2009 to January 2013 and lists the locations of 9150 caught fish, of which $75.9 \%$ were caught in areas we assumed to be fished. This confirmed our assumption that eradication efforts are foremost focused on easily accessible sites according to the definition mentioned above.

On Bonaire, 23 sites were surveyed (Fig. 1). At 12 of these 23 locations, lionfish density and biomass was surveyed in paired sites, of which one was fished $(<150 \mathrm{~m}$ away from access point) and the other was unfished (>200 m away from access point). Since neighboring dive sites were too close to allow for unfished sites in between, some locations on Bonaire could be considered as fished sites only $(n=10)$. One location was considered unfished only, i.e. the Karpata No Diving Reserve, since removal efforts had not been allowed here. Hence, a total of 22 fished and 13 unfished sites were surveyed on Bonaire. On Curaçao, 11 sites were surveyed that were all considered unfished as removal efforts had not yet started on this island at the time of our surveys (Fig. 1).

\section{Fish surveys}

At all fished and unfished sites, four $50 \times 4 \mathrm{~m}$ belt transects were laid out parallel to shore at each depth $(15,25$ and $35 \mathrm{~m})$, resulting in a total of 12 transects per site. At each depth, the 4 transects were separated by a distance of $5 \mathrm{~m}$. A diver recorded all lionfish in each transect by intensively searching in holes, in crevices or under ledges. This method is known to yield similar density and biomass data compared to methods whereby all fish hiding in the reef structure are chemically killed using Rotenone and counted (Kulbicki et al. 2012). The size (total length [TL]) of each individual was then measured to the closest $\mathrm{cm}$ by holding a ruler next to the fish. These measurements were later converted to weight estimates $(W)$ in $g$ using the following standard weight-length relationship for fish (Froese \& Pauly 2010):

$$
W=0.00002285(\mathrm{TL} \times 10)^{2.89}
$$

This relationship $(\mathrm{r}=0.96)$ was previously calculated from 1450 collected lionfish on Bonaire ranging in size

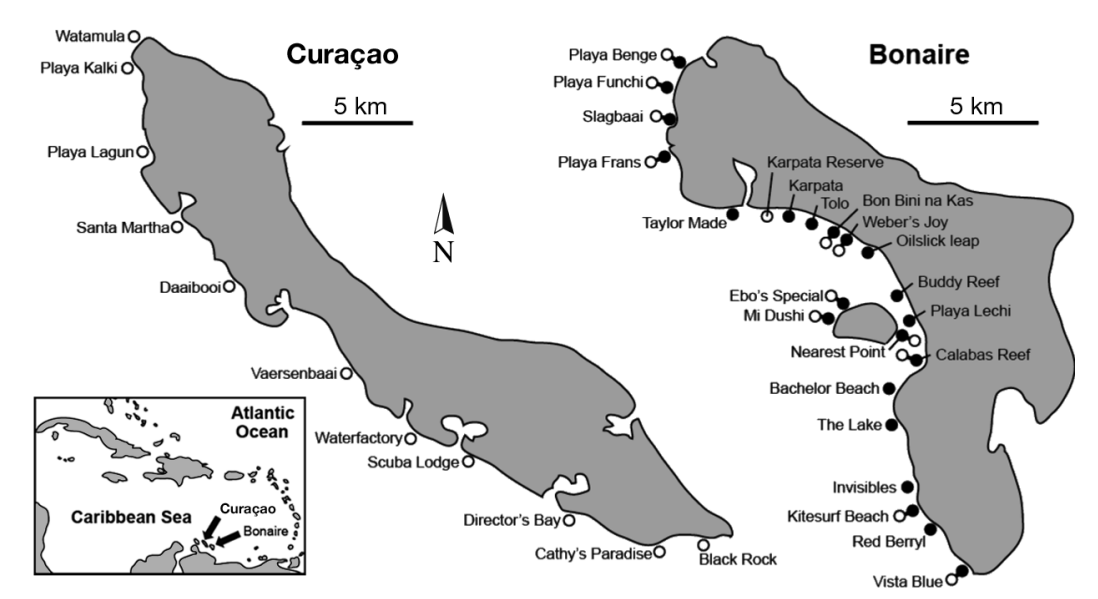

Fig. 1. Surveyed locations on the leeward side of Curaçao and Bonaire. Open circles indicate locations where lionfish were not fished in 2011; closed circles indicate fished locations. Neighbouring black and white circles at certain locations on Bonaire indicate that surveys at 1 location were conducted at a fished site and an unfished site nearby $(>200 \mathrm{~m})$ 
from 2.5 to $40.2 \mathrm{~cm}$. For each transect, biomass estimates per area $\left(\mathrm{g} \mathrm{m}^{-2}\right)$ were obtained by dividing the sum of all weight estimates by the area surveyed (i.e. $200 \mathrm{~m}^{2}$ ). All surveys were conducted by the same surveyors, and because lionfish were easily approachable by divers, we did not consider the possibility that the presence of divers caused them to hide or move away, which would have led to an underestimation of lionfish density or biomass in areas frequently visited by divers. On Bonaire, the 3-dimensional complexity of the benthos was recorded for each site depth combination by assigning 1 of 3 qualitative categories: 'High' for reef communities dominated by large framework-building corals ( $>1 \mathrm{~m}$ in diameter) and characterized by large holes and cavities $(>0.5 \mathrm{~m}$ in diameter) in the reef framework; 'Medium', similar to High but lacking large holes and cavities in the reef framework; and 'Low' for reef communities dominated by coral colonies $<1 \mathrm{~m}$ in diameter. Habitat complexity was included to determine whether lionfish density and biomass was higher in more structurally complex reef environments.

\section{Analyses and statistics}

Data on lionfish density and biomass were nonnormal, even after applying commonly used transformations. To determine significant differences in the density $\left(\mathrm{n} \mathrm{m}^{-2}\right)$ and biomass $\left(\mathrm{g} \mathrm{m}^{-2}\right)$ of lionfish between fished and unfished areas, islands and depths, permutational analysis of variance (PERMANOVA; Anderson 2001) was used because (1) it is robust to datasets with many zeros, (2) it allows testing interactions in multivariate data, (3) it makes no assumptions about underlying data distributions, and (4) it is robust to unbalanced designs. PERMANOVA uses a permutation procedure to assess significance and does not rely on the assumption of normality. Analyses were conducted on untransformed data using Bray-Curtis dissimilarities and 9999 permutations. Significant differences in a PERMANOVA approach can result from differences in location, spread or a combination thereof (Anderson 2006). We therefore performed a distance-based test for homogeneity of multivariate dispersion using the program PERMDISP2 (Anderson 2006) to obtain measures of spread using principal coordinate axes (least-absolute-deviation residuals). Again, p-values were obtained by running 9999 permutations. Because fishing status could not be nested within island, as fished areas did not exist on Curaçao, we used the 3 island fishing status combinations (areas) as a fixed factor within which depth was nested.
As our main interest was the differences in lionfish density and biomass between fished and unfished areas, we used both site and transect number to construct replicates for both these factors and their interaction. When a factor with $>2$ levels was identified as significant (at $\alpha=0.05$ ), post-hoc pairwise tests were conducted, again using 9999 permutations. A similar approach was used to compare the density and biomass of lionfish among habitats characterized by different levels of topographical complexity, whereas parametric factorial ANOVAs were used to assess significant differences in average individual lionfish weights and sizes for all aforementioned factors after data had been log-transformed to ensure data normality and homogeneity of variances.

\section{RESULTS}

\section{Comparison between fished and unfished locations}

On Curaçao, lionfish were present in $73.5 \%$ of all ( $\mathrm{n}=147$ ) surveyed transects. On Bonaire, lionfish were present in $54.9 \%$ of transects surveyed in unfished locations $(\mathrm{n}=151)$ and in $37.5 \%$ of all transects surveyed in fished locations $(n=264)$. The average number of lionfish encountered per transect was 0.60 (30 fish ha ${ }^{-1}$ ) in fished locations on Bonaire, 1.32 (66 fish ha ${ }^{-1}$ ) in unfished locations on Bonaire and 2.54 (127 fish ha ${ }^{-1}$ ) in unfished locations on Curaçao. In unfished sites, lionfish biomass on Bonaire ranged between 0.00 and $10.75 \mathrm{~g} \mathrm{~m}^{-2}$, while in fished locations, it ranged between 0.00 and $6.93 \mathrm{~g} \mathrm{~m}^{-2}$. Both of these maximum values resulted from groups of lionfish consisting of 7 and 5 ind. respectively, in the surveyed areas. In Curaçao, where removal efforts had not yet started in 2011, biomass ranged from 0.00 to $18.49 \mathrm{~g} \mathrm{~m}^{-2}$. Again, the high maximum values were caused by groups of lionfish within 1 transect where the aforementioned value corresponded to a group of 16 lionfish.

Lionfish biomass and density differed significantly among the 3 combinations of island and fishing status (Fig. 2, Table 1). A change in lionfish density with depth was only observed in unfished areas on Bonaire (negative relationship) and contributed foremost to the significant interaction term (area $\times$ depth) for lionfish density (post hoc test; $\mathrm{p}<0.05$; Table 1 ). For biomass, the interaction term was also significant (Table 1) and caused by a negative relationship between depth and lionfish biomass in unfished areas on Bonaire and a positive relationship between the same factors in unfished areas on Curaçao (post 

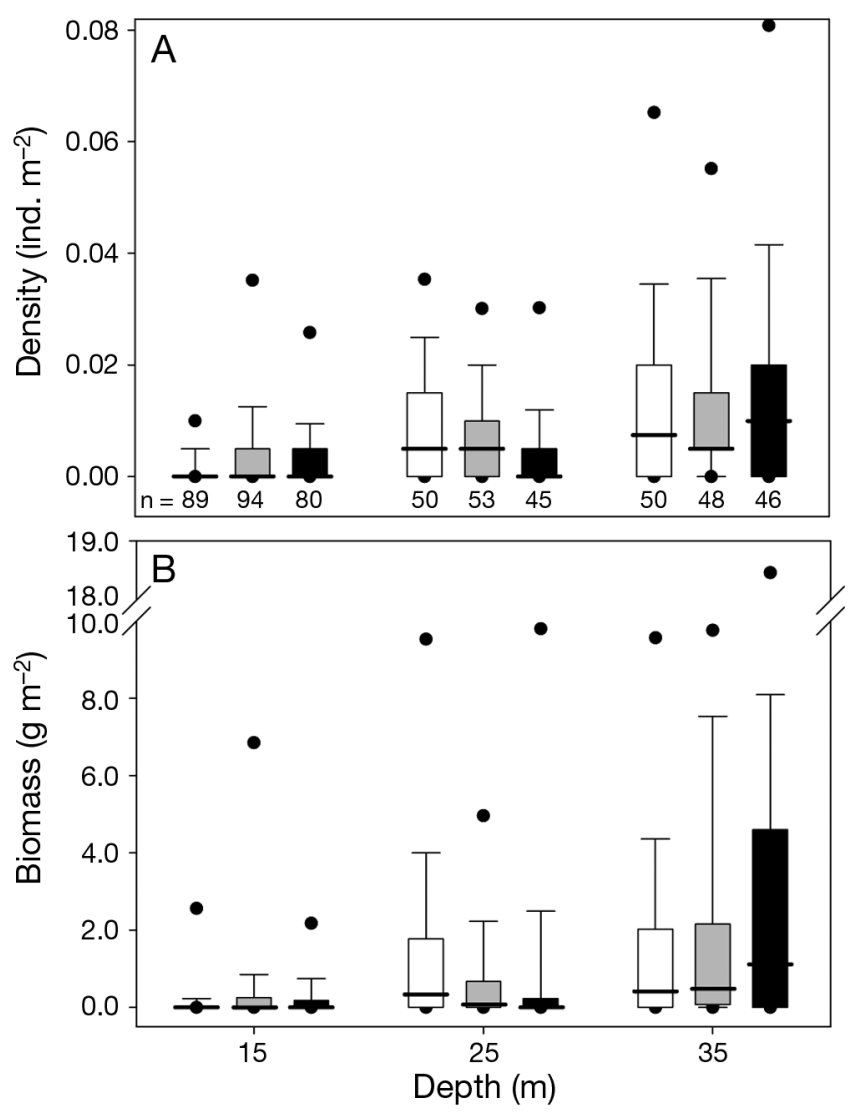

Fig. 2. (A) Lionfish Pterois spp. density, and (B) biomass in fished locations on Bonaire (white) and unfished locations on Bonaire and Curaçao (grey and black, respectively) for 3 different depths. Number of sites surveyed per each combination of factors indicated below boxes in upper panel. Box plots display the interquartile range (box), median (center line in box), 10th and 90th percentiles (whiskers), and minimum and maximum values

Table 1. PERMANOVA results for differences in lionfish Pterois spp. density and biomass among the 3 areas studied: Bonaire (fished), Bonaire (unfished), Curaçao (unfished) and depth

\begin{tabular}{|lrrrrr|}
\hline \multicolumn{1}{l}{ SS } & df & MS & \multicolumn{1}{c|}{$F$} & $\mathrm{p}$ \\
\hline Density & & & & & \\
Area & 316.0 & 2 & 158.0 & 53.2 & $<0.01$ \\
Depth & 10.9 & 2 & 5.4 & 1.8 & 0.13 \\
Interaction & 435.3 & 4 & 108.8 & 36.7 & $<0.01$ \\
Residual & 1641.5 & 553 & 3.0 & & \\
Total & 2403.7 & 561 & & & \\
Biomass & & & & & \\
Area & 362.6 & 2 & 181.3 & 56.0 & $<0.01$ \\
Depth & 1.7 & 2 & 0.9 & 0.26 & 0.75 \\
Interaction & 296.3 & 4 & 74.1 & 22.9 & $<0.01$ \\
Residual & 1788.8 & 553 & 3.2 & & \\
Total & 2449.4 & 561 & & & \\
\hline
\end{tabular}

hoc test; $\mathrm{p}<0.05)$. The test for homogeneity of multivariate dispersions showed that none of the significant differences observed were due to differences in spread (all p > 0.12).

\section{Comparison between fished and unfished locations: size distribution}

The average weight of lionfish in fished areas on Bonaire was less than the average weight of lionfish from unfished areas on both islands (Fig. 3; factorial ANOVA, area $\times$ depth, $F_{2,730}=4.8, \mathrm{p}<0.001$, followed by Tukey post-hoc tests; $\mathrm{p}<0.01$ ). The significant interaction term resulted from a positive relationship between mean lionfish weight and depth in unfished areas on Curaçao (post-hoc tests; $\mathrm{p}<0.01$ ). The average length of lionfish followed a pattern similar to average lionfish weight, with the average length in fished areas on Bonaire being 15 to $26 \%$ smaller than in unfished areas on both islands (Fig. 4 ; ANOVA, $F_{2,395}=12.2$, $\mathrm{p}<0.001$, followed by Tukey post-hoc tests; $\mathrm{p}<0.01$ ).

\section{Influence of habitat complexity}

Data on habitat complexity was only collected on Bonaire, and approximately the same number of habitat type $\times$ depth combinations were sampled in

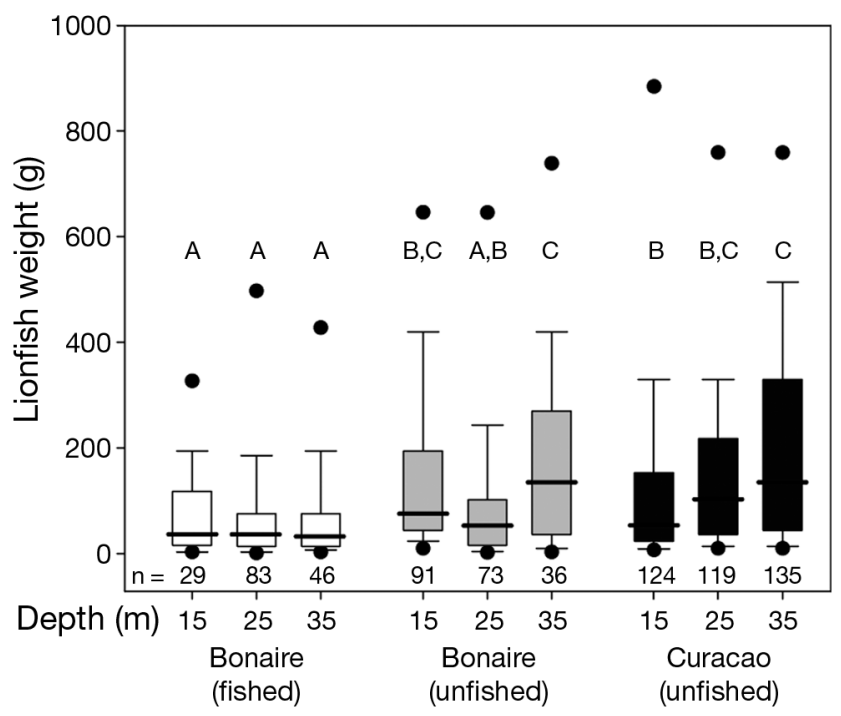

Fig. 3. Effect of depth and fishing on the weight of individual lionfish Pterois spp. Number of sites surveyed per each combination of factors indicated below boxes. Box plots display the interquartile range (box), median (center line in box), 10th and 90th percentiles (whiskers) and minimum and maximum values (black dots). Same letters indicate factor combinations that are not significantly different from each other 


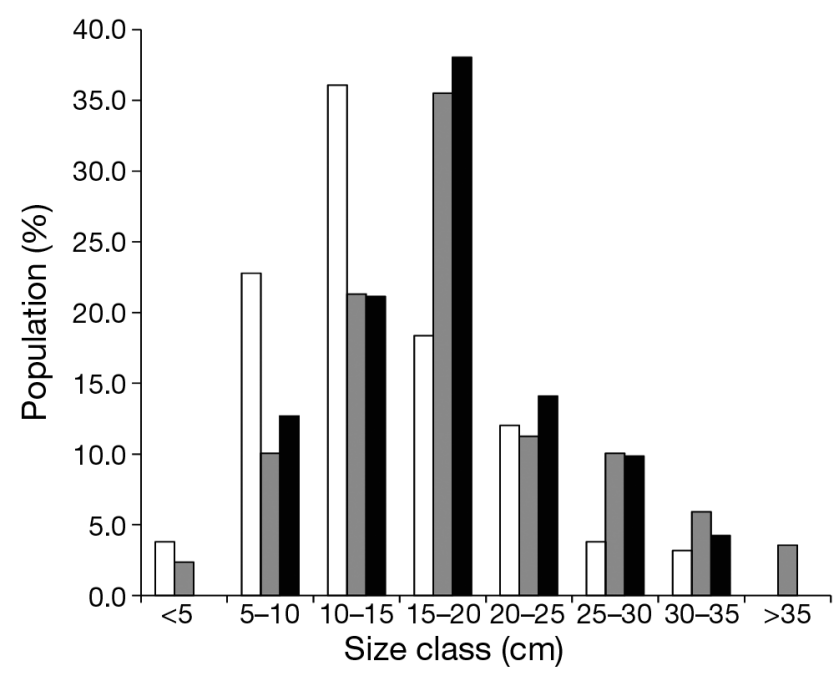

Fig. 4. Lionfish Pterois spp. size frequency distributions in fished ( $\mathrm{n}=158$; white) and unfished locations on Bonaire ( $\mathrm{n}=200$; grey) and in unfished locations in Curaçao ( $\mathrm{n}=378$; black)

fished and unfished areas. Although lionfish density and biomass significantly differed among habitat types (PERMANOVA; $F_{2,351}=3.53$ and 3.95 respectively; $\mathrm{p}<0.001)$ and fished vs. unfished areas (PERMANOVA; $F_{1,351}=5.09$ and 5.36 respectively; $\mathrm{p}<0.001$ ), the expected relationship between increased habitat complexity and increased lionfish

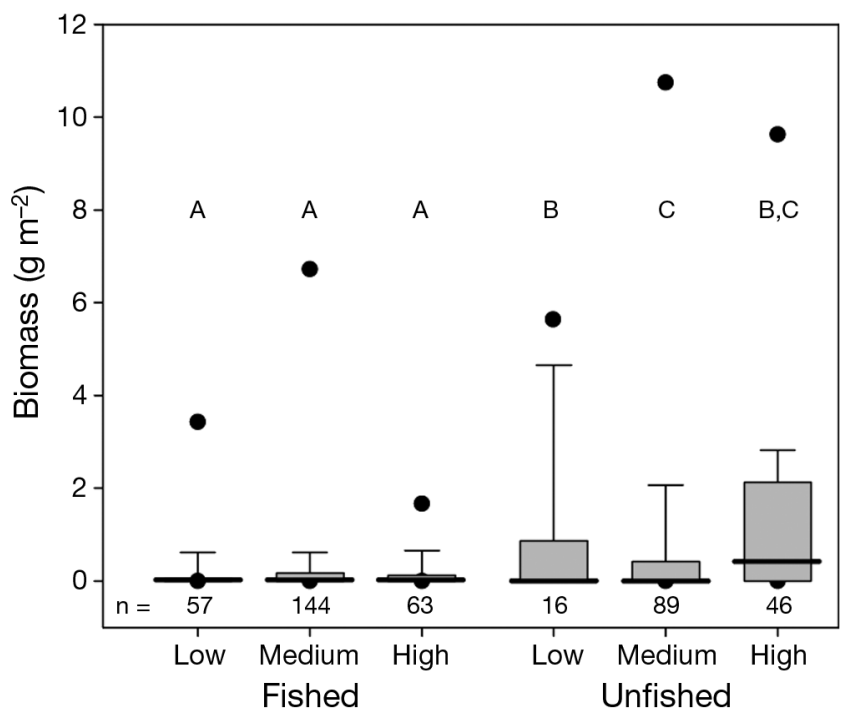

Fig. 5. Average lionfish Pterois spp. biomass in sites characterized by high, medium and low habitat complexity in fished and unfished locations on Bonaire. Number of sites surveyed per each combination of factors indicated below boxes. Box plots display the interquartile range (box), median (center line in box), 10th and 90th percentiles (whiskers), and minimum and maximum values (black dots). Same letters indicate factor combinations that are not significantly different from each other density or biomass could not be supported (Fig. 5). Lionfish density and biomass were low overall and did not differ among habitat types in fished areas (post-hoc tests; $p>0.05$ ); in the unfished areas they were lowest in habitats of intermediate complexity (post-hoc tests; $p$ > 0.05). Again, none of the significant differences observed were due to differences in spread (test for homogeneity of multivariate dispersions; $\mathrm{p}>0.10$ ).

In summary, the biomass (in $\mathrm{g} \mathrm{m}^{-2}$ ) of lionfish in fished locations on Bonaire was 2.76-fold less compared to unfished areas on the same island and 4.14fold lower than on unfished Curaçao. Secondly, the density of lionfish (ind. $\mathrm{m}^{-2}$ ) in fished locations on Bonaire was 2.21-fold lower than in unfished areas on the same island and 4.25-fold lower than on unfished Curaçao. Lastly, the average weight of individual lionfish in fished locations on Bonaire was 1.83-fold less than in unfished locations on the same island and 2.24-fold less than on unfished Curaçao.

\section{DISCUSSION}

The present study strongly suggests that removal efforts on Bonaire are effective in reducing the number (i.e. the rate at which lionfish populations increase) and size of invasive lionfish between depths of 15 and $35 \mathrm{~m}$. Lionfish biomass is on average 2.76fold less in fished areas on Bonaire than in nearby unfished areas on the same island and 4.14-fold less than on nearby Curaçao where eradication efforts had not yet started when the present study took place. Between the depths at which the present study was conducted, the reef communities on both islands are very similar (van Duyl 1985, Van Veghel 1997, Sandin et al. 2007), minimizing the possibility that spatial variability in reef community structure caused the observed differences in lionfish biomass and density between the 2 islands. Our initial hypothesis that lionfish preferred highly complex reefscapes was not supported (Fig. 5) although previous studies (Fishelson 1975, Biggs \& Olden 2011, Jud et al. 2011, Jud \& Layman 2012) have found lionfish to prefer complex landscapes in a variety of marine habitat types. Because both islands were invaded simultaneously in October 2009, our findings likely portray the outcome of 2 different local management approaches, i.e. the one on Curaçao (no response) and the one on Bonaire (immediate response). The immediate initiation of organized, local removal efforts on Bonaire by training many $( \pm 300)$ local divers for lionfish removal efforts has resulted in lowered lionfish biomass and 
density relative to unfished sites on the leeward side of the same island within $2 \mathrm{yr}$ after the first lionfish was sighted. A rapid (local) response to reduce the abundance of invasive species is widely accepted as the most efficient methodology to reduce excessive growth of invasive populations (Culver \& Kuris 2000, Secord 2003, Wotton et al. 2004, Anderson 2005), and the present study shows that such local management interventions to reduce the local number of lionfish can be successful, as has been shown elsewhere in the Caribbean (Frazer et al. 2012).

That Bonaire has easily accessible reef sites along its entire leeward coast likely contributed to the success of local removal efforts. Unfished locations on Bonaire that often bordered fished locations (Fig. 1) also showed an average reduction in lionfish biomass of $28 \%$ relative to unfished locations on Curaçao, which is probably related to the fact that some people still target these areas to remove lionfish. Based on actual catch data (see www.lionfishcontrol.org), the intensity of removal efforts is 3.1-fold lower in areas we assumed to be 'unfished' compared to 'fished' areas, and while substantially less, fishing in sites we assumed to be unfished could explain the $28 \%$ reduction in lionfish biomass at these sites.

For lionfish, a removal rate between 35 and $65 \%$ of the adult biomass per year (Barbour et al. 2011) or a monthly $27 \%$ reduction in adult lionfish density are required to significantly reduce population renewal (Morris et al. 2011b). The $>2$-fold reduction in lionfish density and biomass in fished locations on Bonaire suggests that present removal efforts exceed aforementioned removal rates estimated to achieve negative population growth on a local level. Removal efforts involving hundreds of volunteer divers thus generate removal rates high enough to reduce the local population of lionfish, confirming similar observations elsewhere in the Caribbean (Frazer et al. 2012).

Larger lionfish generally occurred at greater depths (Fig. 3). Size differences of lionfish across depth have been associated with ontogenic shifts from shallow to deeper reefs as individual fish mature (Barbour et al. 2010, Biggs \& Olden 2011, Claydon et al. 2012). Such behavior likely reduces the effectiveness of local removal efforts as large, and therefore more fecund, lionfish occur at depths largely inaccessible for divers. Complete removal will thus be impossible as lionfish populations on the windward sides of both islands and those below traditional diving limits (i.e. $\sim 40 \mathrm{~m}$ ) remain largely unfished. In addition to the influx of larvae from other Caribbean locations (Ahrenholz \& Morris 2010, Johnston \& Purkis 2011, Vásquez-Yeomans et al. 2011), larvae produced by these locally unfished populations will likely permanently offset the effect of removals on the leeward side assuming that local retention of larvae occurs to some degree. Lionfish control efforts can therefore never cease as local populations are likely replenished by recruitment from external sources and native predators feeding on or learning to feed on lionfish are presently rare throughout the Caribbean (Mumby et al. 2011). Although the present study strongly suggests that removal efforts on Bonaire are effective in reducing the number and size of invasive lionfish, it remains unknown if the reduction in lionfish results in any ecological benefit. Nevertheless, our data show that local removal efforts using volunteers represent a cost-effective, rapid-response option that is successful at significantly reducing the density and biomass of invasive lionfish on a small Caribbean island.

Acknowledgements. This study was made possible in part through funding to M.J.A.V. from the Government of Curaçao.

\section{LITERATURE CITED}

Ahrenholz DW, Morris JA (2010) Larval duration of the lionfish, Pterois volitans along the Bahamian archipelago. Environ Biol Fishes 88:305-309

Albins MA (2013) Effects of invasive Pacific red lionfish Pterois volitans versus a native predator on Bahamian coral-reef fish communities. Biol Invasions 15:29-43

Albins MA, Hixon MA (2008) Invasive Indo-Pacific lionfish Pterois volitans reduce recruitment of Atlantic coral-reef fishes. Mar Ecol Prog Ser 367:233-238

Albins MA, Hixon MA (2013) Worst case scenario: potential long-term effects of invasive predatory lionfish (Pterois volitans) on Atlantic and Caribbean coral-reef communities. Environ Biol Fishes 96:1151-1157

Anderson MJ (2001) A new method for non parametric multivariate analysis of variance. Austral Ecol 26:32-46

> Anderson LW (2005) California's reaction to Caulerpa taxifolia: a model for invasive species rapid response. Biol Invasions 7:1003-1016

> Anderson MJ (2006) Distance based tests for homogeneity of multivariate dispersions. Biometrics 62:245-253

> Arias-González JE, González-Gándara C, Luis Cabrera J, Christensen V (2011) Predicted impact of the invasive lionfish Pterois volitans on the food web of a Caribbean coral reef. Environ Res 111:917-925

Barbour AB, Montgomery ML, Adamson AA, Díaz-Ferguson E, Silliman BR (2010) Mangrove use by the invasive lionfish Pterois volitans. Mar Ecol Prog Ser 401:291-294

> Barbour AB, Allen MS, Frazer TK, Sherman KD (2011) Evaluating the potential efficacy of invasive lionfish (Pterois volitans) removals. PLoS ONE 6:e19666

Bax N, Carlton J, Mathews Amos A, Haedrich R and others (2001) The control of biological invasions in the world's oceans. Conserv Biol 15:1234-1246

> Bax N, Williamson A, Aguero M, Gonzalez E, Geeves W (2003) Marine invasive alien species: a threat to global biodiversity. Mar Policy 27:313-323 
Biggs CR, Olden JD (2011) Multi-scale habitat occupancy of invasive lionfish (Pterois volitans) in coral reef environments of Roatan, Honduras. Aquat Invasions 6: 347-353

> Chollett I, Mumby PJ, Müller-Karger FE, Hu C (2012) Physical environments of the Caribbean sea. Limnol Oceanogr 57:1233-1244

Claydon JAB, Calosso MC, Traiger SB (2012) Progression of invasive lionfish in seagrass, mangrove and reef habitats. Mar Ecol Prog Ser 448:119-129

Côté IM, Maljković A (2010) Predation rates of Indo-Pacific lionfish on Bahamian coral reefs. Mar Ecol Prog Ser 404: 219-225

- Culver CS, Kuris AM (2000) The apparent eradication of a locally established introduced marine pest. Biol Invasions 2:245-253

Darling ES, Green SJ, O'Leary JK, Côté IM (2011) IndoPacific lionfish are larger and more abundant on invaded reefs: a comparison of Kenyan and Bahamian lionfish populations. Biol Invasions 13:2045-2051

Fishelson L (1975) Ethology and reproduction of pteroid fishes found in the Gulf of Aqaba (Red Sea), especially Dendrochirus brachypterus (Cuvier), (Pteroidae, Teleostei). Pubbl Stn Zool Napoli 39:635-656

> Frazer TK, Jacoby CA, Edwards MA, Barry SC, Manfrino CM (2012) Coping with the lionfish invasion: Can targeted removals yield beneficial effects? Rev Fish Sci 20: 185-191

Froese R, Pauly D (eds) (2010) FishBase. www.fishbase.org (accessed October 2013)

Genovesi P (2005) Eradications of invasive alien species in Europe: a review. Issues Bioinvasion Sci 7:127-133

Green SJ, Akins JL, Côté IM (2011) Foraging behaviour and prey consumption in the Indo-Pacific lionfish on Bahamian coral reefs. Mar Ecol Prog Ser 433:159-167

Hawkins JP, Roberts CM, Van'T Hof T, De Meyer K, Tratalos J, Aldam C (1999) Effects of recreational scuba diving on Caribbean coral and fish communities. Conserv Biol 13:888-897

Hewitt CL, Everett RA, Parker N (2009) Examples of current international, regional and national regulatory frameworks for preventing and managing marine bioinvasions. In: Rilov G, Crooks GA (eds) Biological invasions in marine ecosystems. Springer, Heidelberg, p 335-352

> Johnston MW, Purkis SJ (2011) Spatial analysis of the invasion of lionfish in the western Atlantic and Caribbean. Mar Pollut Bull 62:1218-1226

Johnston EL, Piola RF, Clark GF (2009) The role of propagule pressure in invasion success. In: Rilov G, Crooks JA (eds) Biological invasions in marine ecosystems. Springer, Heidelberg, p 133-151

> Jud ZR, Layman CA (2012) Site fidelity and movement patterns of invasive lionfish, Pterois spp., in a Florida estuary. J Exp Mar Biol Ecol 414-415:69-74

Jud ZR, Layman CA, Lee JA, Arrington DA (2011) Recent invasion of a Florida (USA) estuarine system by lionfish Pterois volitans/P. miles. Aquat Biol 13:21-26

Kulbicki M, Beets J, Chabanet P, Cure K and others (2012) Distributions of Indo-Pacific lionfishes Pterois spp. in their native ranges: implications for the Atlantic invasion. Mar Ecol Prog Ser 446:189-205

Lafferty KD, Kuris AM (1996) Biological control of marine pests. Ecology 77:1989-2000

Layman CA, Allgeier JE (2012) Characterizing trophic ecology of generalist consumers: a case study of the invasive lionfish in The Bahamas. Mar Ecol Prog Ser 448:131-141
Maljković A, Van Leeuwen T, Cove S (2008) Predation on the invasive red lionfish, Pterois volitans (Pisces: Scorpaenidae), by native groupers in the Bahamas. Coral Reefs 27:501

Morris JA Jr (2009) The biology and ecology of the invasive Indo-Pacific lionfish. PhD dissertation, NC State University, Raleigh, NC

Morris JA Jr, Akins JL (2009) Feeding ecology of invasive lionfish (Pterois volitans) in the Bahamian archipelago. Environ Biol Fishes 86:389-398

Morris JA Jr, Sullivan CV, Govoni JJ (2011a) Oogenesis and spawn formation in the invasive lionfish, Pterois miles and Pterois volitans. Sci Mar 75:147-154

Morris JA Jr, Shertzer KW, Rice JA (2011b) A stage-based matrix population model of invasive lionfish with implications for control. Biol Invasions 13:7-12

Mumby PJ, Harborne AR, Brumbaugh DR (2011) Grouper as a natural biocontrol of invasive lionfish. PLoS ONE 6: e21510

> Muñoz RC, Currin CA, Whitfield PE (2011) Diet of invasive lionfish on hard bottom reefs of the Southeast USA: insights from stomach contents and stable isotopes. Mar Ecol Prog Ser 432:181-193

> Rouphael AB, Inglis GJ (2002) Increased spatial and temporal variability in coral damage caused by recreational scuba diving. Ecol Appl 12:427-440

Sandin SA, Sampayo EM, Vermeij MJA (2007) Coral reef fish and benthic community structure of Bonaire and Curaçao, Netherlands Antilles. Caribb J Sci 44:137-144

Schofield PJ (2009) Geographic extent and chronology of the invasion of non-native lionfish (Pterois volitans [Linnaeus 1758] and $P$. miles [Bennett 1828]) in the western north Atlantic and Caribbean sea. Aquat Invasions 4: 473-479

Schofield PJ (2010) Update on geographic spread of invasive lionfishes (Pterois volitans [Linnaeus, 1758] and P. miles [Bennett, 1828]) in the western North Atlantic Ocean, Caribbean Sea and Gulf of Mexico. Aquat Invasions 5: S117-S122

- Secord D (2003) Biological control of marine invasive species: cautionary tales and land-based lessons. Biol Invasions 5:117-131

> Semmens BX, Buhle ER, Salomon AK, Pattengill-Semmens CV (2004) A hotspot of non-native marine fishes: evidence for the aquarium trade as an invasion pathway. Mar Ecol Prog Ser 266:239-244

> Valdez-Moreno M, Quintal-Lizama C, Gómez-Lozano R, del Carmen García-Rivas M (2012) Monitoring an alien invasion: DNA barcoding and the identification of lionfish and their prey on coral reefs of the Mexican Caribbean. PLoS ONE 7:e36636

van Duyl FC (1985) Atlas of the living reefs of Curaçao and Bonaire (Netherlands Antilles). Naturwetenschappelijke Studiekring voor Suriname en de Nederlandse Antillen, Utrecht

Van Veghel M (1997) A field guide to the reefs of Curacao and Bonaire. Proc 8th Int Coral Reef Symp 1:223-234

Vásquez-Yeomans L, Carrillo L, Morales S, Malca E, Morris JA, Schultz T, Lamkin JT (2011) First larval record of Pterois volitans (Pisces: Scorpaenidae) collected from the ichthyoplankton in the Atlantic. Biol Invasions 13: 2635-2640

> Wotton DM, O'Brien C, Stuart MD, Fergus DJ (2004) Eradication success down under: heat treatment of a sunken trawler to kill the invasive seaweed Undaria pinnatifida. Mar Pollut Bull 49:844-849

Submitted: February 17, 2013; Accepted: August 26, 2013

Proofs received from author(s): November 15, 2013 